Bull. Fac.Agric.,Cairo Univ., 63: 120- 129 (2012).

\title{
COMPARISON OF SOME GENOTYPES OF DURUM WHEAT FOR GROWING AND PRODUCTION
}

(Received:11.3.2012)

\author{
By \\ H. M. M. Al- Fahdawi \\ Center of Desert Studies- University of @Anbar-Iraq
}

\begin{abstract}
Eight wheat genotypes, seven mutations $(7,26,38,49,53,63,82)$ and durum wheat (door 85) were grown in sandy loam soil at winter season 2009 / 2010 , in Al -Sufia District, a rural area in Ramadi city . Genotypes input with randomized block design in three replicates were used. The aim of the experiment is to understand how these genotypes are grown and produce in the west of Iraq . The number of tillers/ plant ,plant height, length of flag leaf, spike length, number of grains / spike, 1000 grains, date of maturity , lodging and grain yield were measured. Genotypes did not differ significantly in grain yield, number of grains / spike , number of tillers, plant height and spike length. Mutation (7) gave high rate of grain yield(4.62 $\mathrm{t}^{-1} \mathrm{~h}^{-1}$ ) and number of grains /spike (63.1). Whereas genotypes were significantly different in weight of 1000 grains and flag leaf length. Durum wheat (door 85) gave the highest rate of 1000 grains weight about $48.6 \mathrm{gm}$ and flag leaf length $24.8 \mathrm{~cm}$. Genotypes were different from each other in physiological maturity, door 85 cultivar and mutation 26 came early at 11 April, while mutation (82) late at 17 April, and length of maturity period was about $10-13$ days for each genotype.

The genotypes were slightly or medium resistant of lodging. The genotype of durum wheat is growing naturally and gives economic yield.
\end{abstract}

Key words: durum wheat, genotypes, growth, mutation,production.

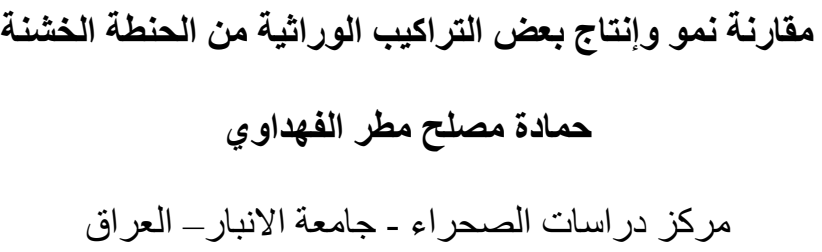

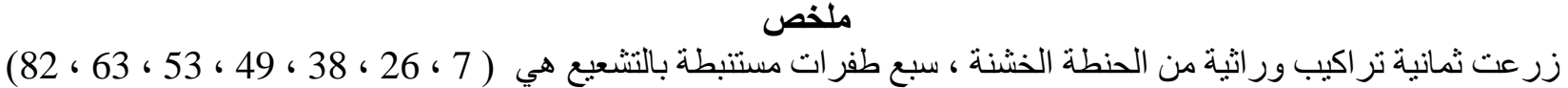

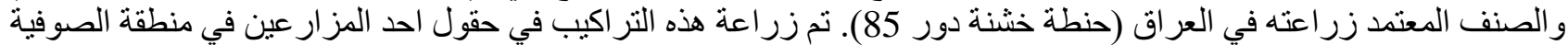

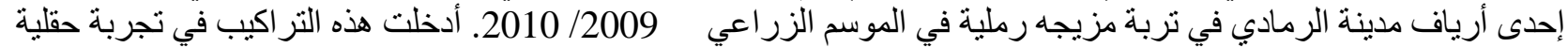

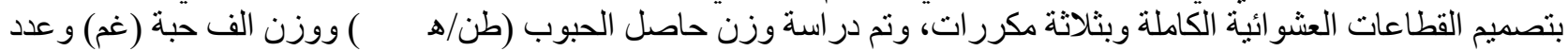

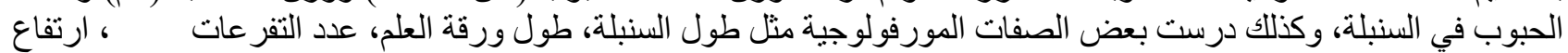

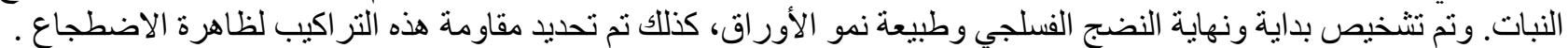

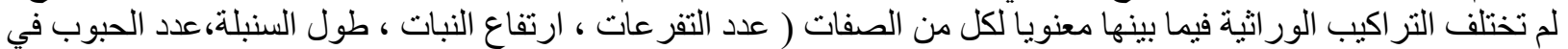

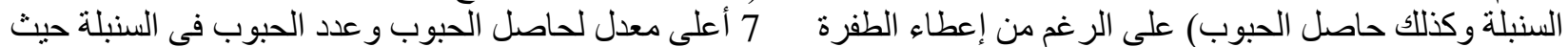

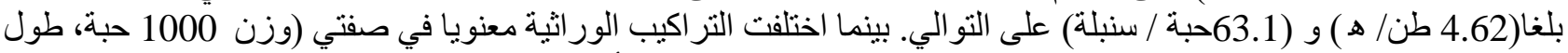

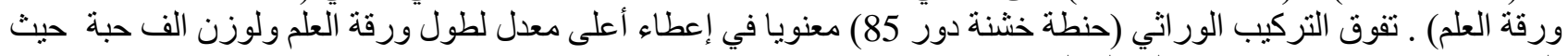
بلغا (24.8 سم) و (48.6 غم ) على التو الي. 


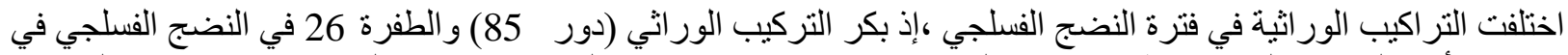

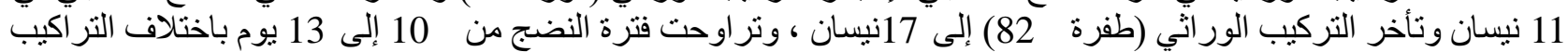

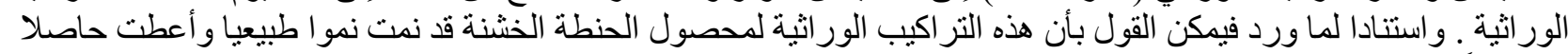

اقتصادياً تحت ظروف منطقة الرمادي العر اقية.

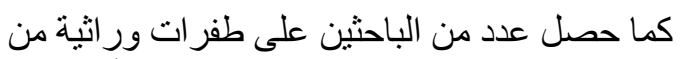

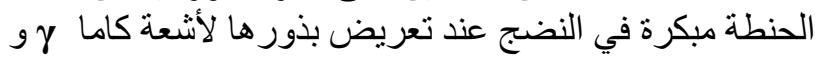

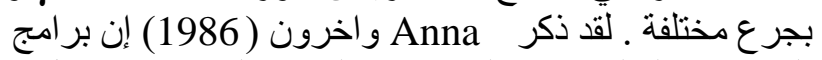
التربية في العالم تركز على تحسين الحنطة الخشنة من خلن خلال

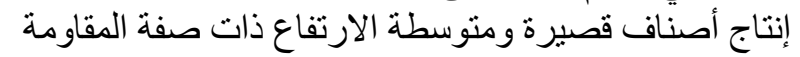
للاضطجاع أنتاج و علية بذلت جهود كبيرة من قبل بعض العلماء في العباء العراق

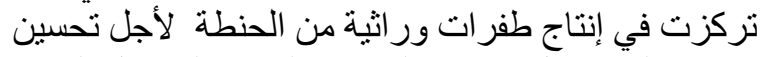

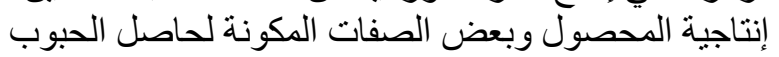

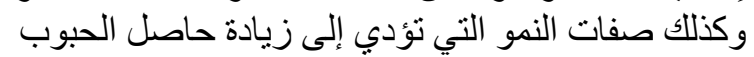

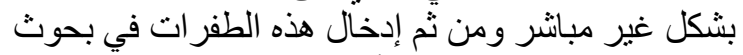

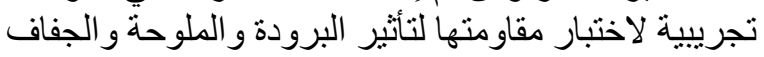

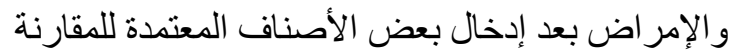

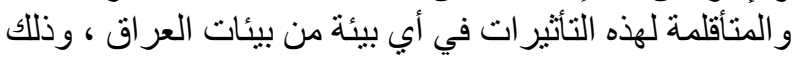

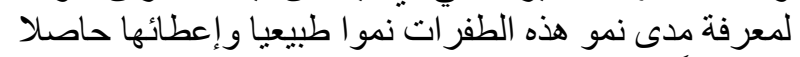
اقتصادياً .

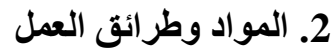

تم الحصول على بذور بعض التر اكيب الور اثية للحنطة العبل

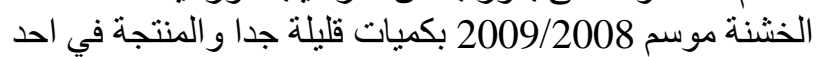

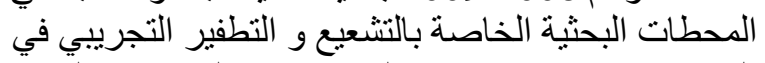

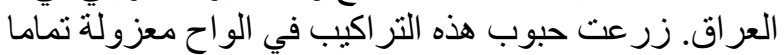

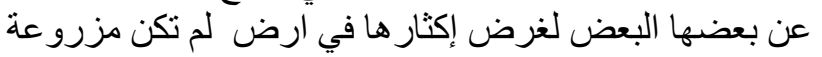

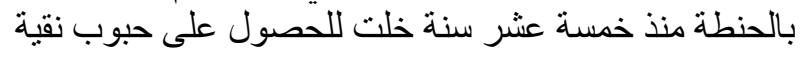

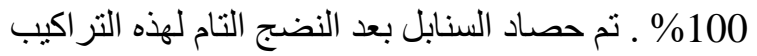

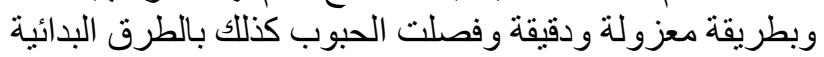

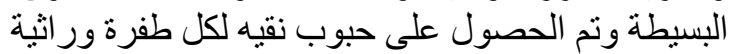

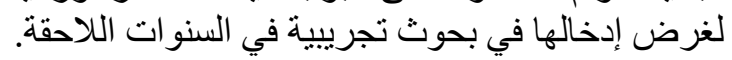

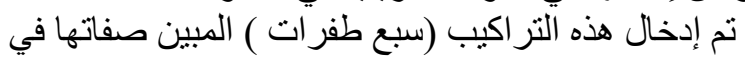

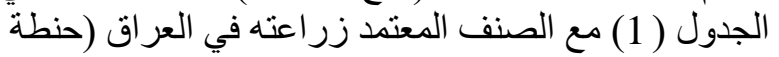

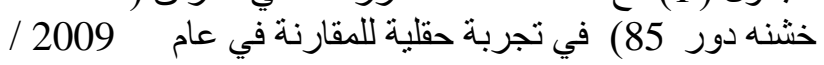

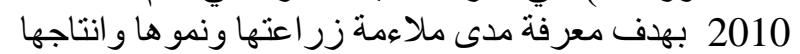

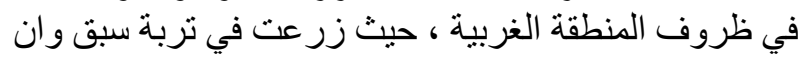

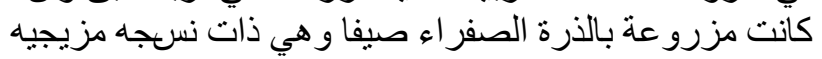

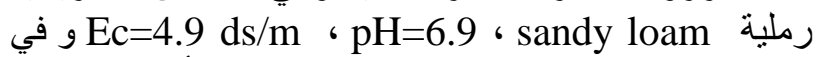
حقول احد المزارعين في منطقة الصوفية إحدى أرياف مدينة

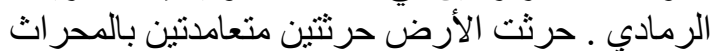
المطرحي القلاب وتم تتعيمها باستخدام آلة الأمشاط النين بالنيضية.

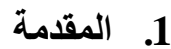

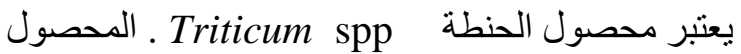

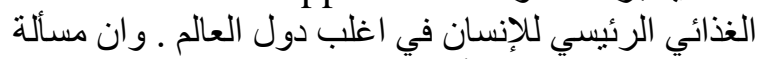

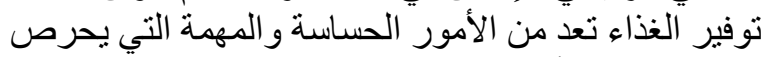

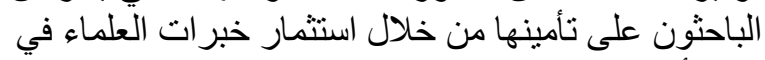

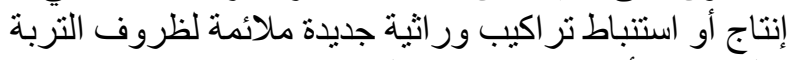

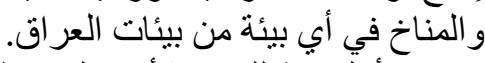

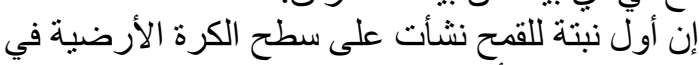

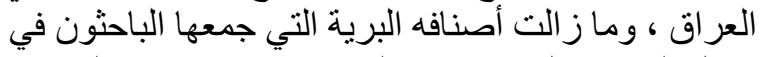

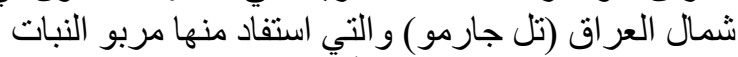

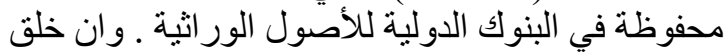

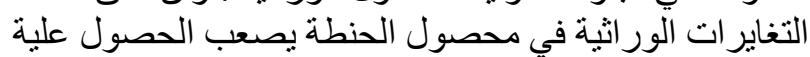

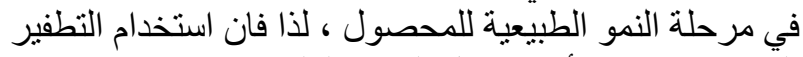

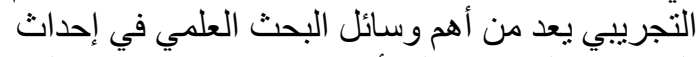

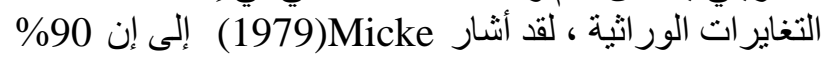

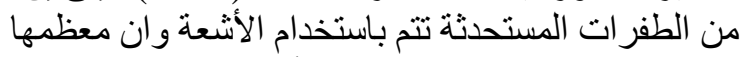

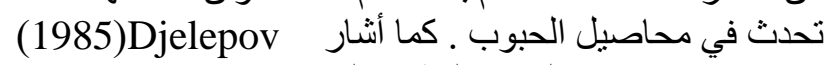

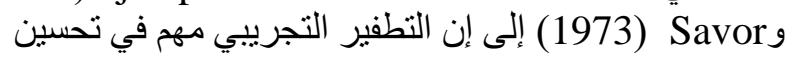

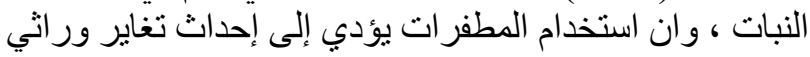

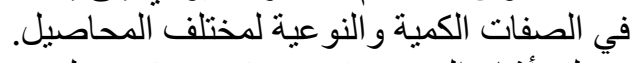

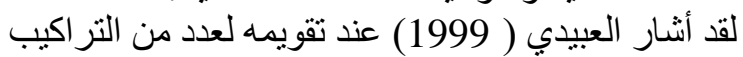

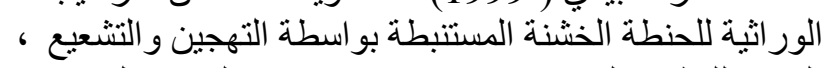

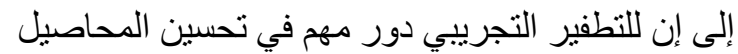

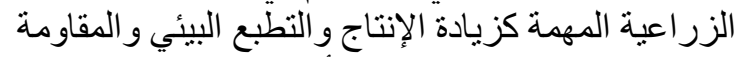

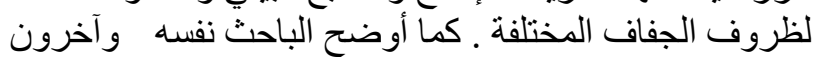

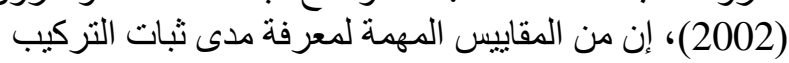

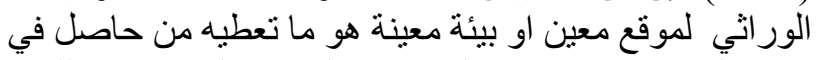
وحدة المساحة وثبات هذه الصفة في المواسم اللاحقة في ذلك إن بعض الصفات المورفولوجية والتي لها علاقة غير الموقع.

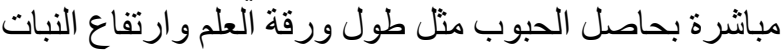

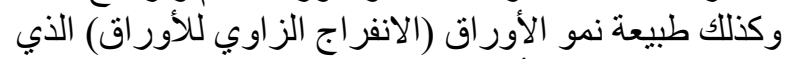

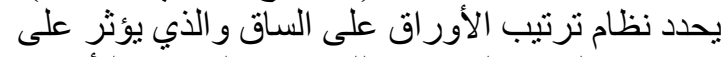

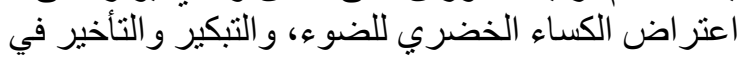

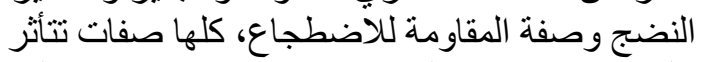

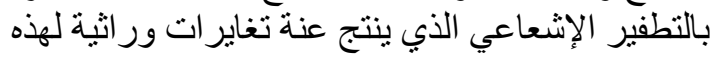

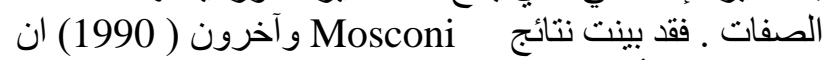

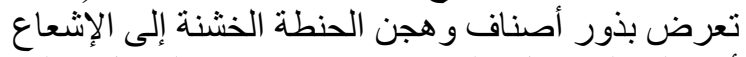

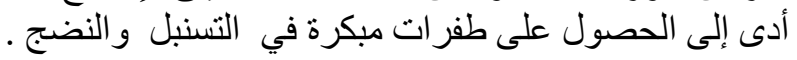


جدول (1): الصفات المورفولوجية وبعض صفات النمو والحاصل للتراكيب الوراثية في موسم 2008 / 2009 ـ

\begin{tabular}{|c|c|c|c|c|c|c|c|c|c|c|}
\hline \multirow{2}{*}{ طبيعة نمو } & \multicolumn{3}{|c|}{ النضج الفسلجي } & \multirow{2}{*}{ وزن الحبوبة في (غم) } & \multirow{2}{*}{ عدد الحبوب في } & \multirow{2}{*}{ طول السنبلة } & \multirow{2}{*}{ طول ورقة } & \multirow{2}{*}{$\begin{array}{c}\text { ارتفاع النبات } \\
\text { (سم) }\end{array}$} & \multirow[b]{2}{*}{ عدد التفرعات } & \multirow[b]{2}{*}{ التراكيب الوراثية } \\
\hline & طول الفترة & نهايته & بايته & & & & & & & \\
\hline أفقي & 10 & 28 نيسان & 18 نيسان & 2.5 & 50.2 & 7.9 & 24.9 & 84.1 & 2.3 & حنطة خشنة دور \\
\hline أفقي & 11 & 30 نيسان & 19 نيسان & 2.8 & 57.6 & 7.5 & 24.8 & 83.3 & 3.0 & $\begin{array}{l}\text { cod } 68 \\
26 \text { طفرة }\end{array}$ \\
\hline أفقي & 11 & 2 مايس & 21 نيسان & 2.9 & 56.6 & 7.9 & 25.3 & 90.5 & 2.3 & $\begin{array}{l}\text { cod } 68 \\
38 \text { طفرة }\end{array}$ \\
\hline عمودي & 13 & 28 نيسان & 15 نيسان & 3.0 & 70.0 & 6.4 & 19.1 & 81.5 & 3.2 & $\begin{array}{l}\text { طفرة } 788 \\
7\end{array}$ \\
\hline عمودي & 12 & 4 مايس & 22 نيسان & 2.8 & 58.6 & 7.3 & 20.8 & 86.6 & 3.8 & $\begin{array}{c}\operatorname{cod} 68 \\
49 \text { طفرة }\end{array}$ \\
\hline عمودي & 14 & 3 مايس & 18 نيسان & 2.2 & 48.5 & 7.8 & 20.8 & 83.6 & 3.5 & $\begin{array}{c}\operatorname{cod} 78 \\
53 \text { طفرة }\end{array}$ \\
\hline عمودي & 10 & 30 نيسان & 20 نيسان & 2.4 & 46.4 & 7.2 & 24.9 & 84.2 & 3.5 & $\begin{array}{c}\operatorname{cod} 68 \\
63 \text { طفرة }\end{array}$ \\
\hline عمودي & 12 & 3 مايس & 21 نيسان & 2.6 & 55.7 & 7.6 & 21.2 & 85.1 & 4.6 & $\begin{array}{c}\text { cod } 68 \\
82 \text { طفرة }\end{array}$ \\
\hline
\end{tabular}




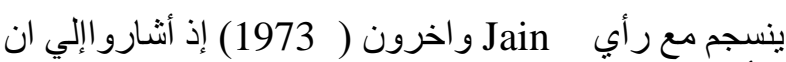

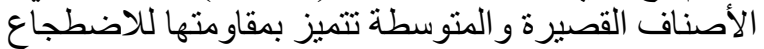

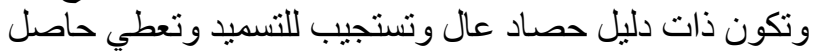

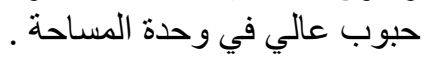
اما بالنسبة لصفية طول ورة الصة العة العلم ، فيتضح من الجدول ذاته تفوق الصنف المعتمد ( دور

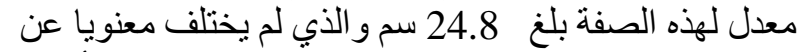

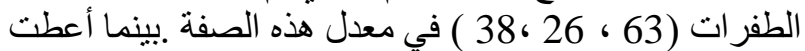

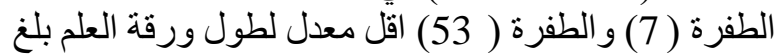

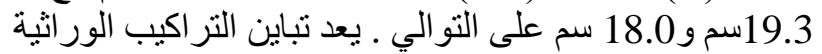

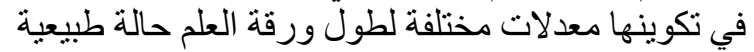
لكونها صفة ور اثية مرتبطة بطبيعة التركيب الور اثي ذاته

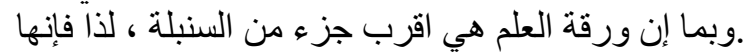

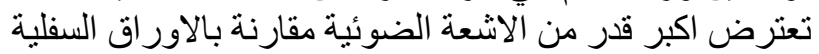

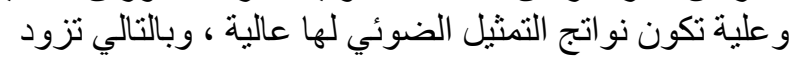
الحبوب بقدر كاف من المو اد الغذائية المصنعة التئة 2.3. 2.3. الحاصل ومكوناته.

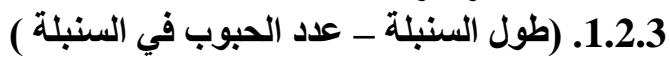

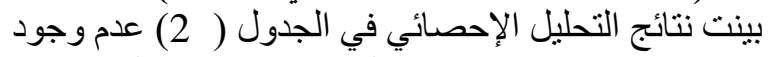
فروق معنوية بين معدلات هاتين الصفتنين باختلاف التنر اكيب التيب

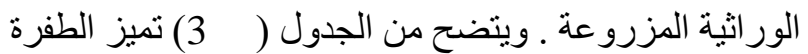

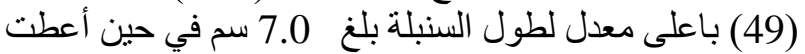

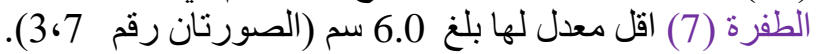

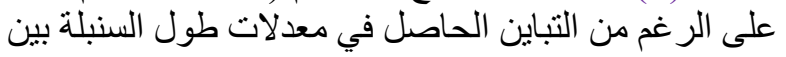

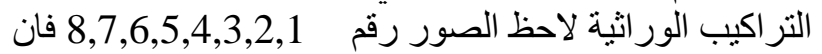

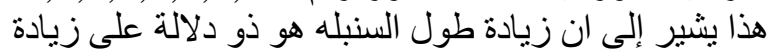

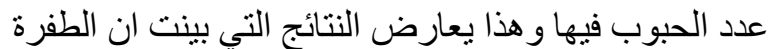

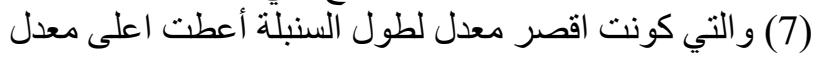

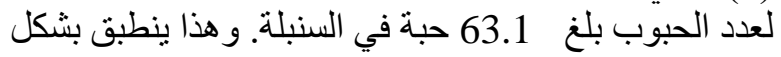

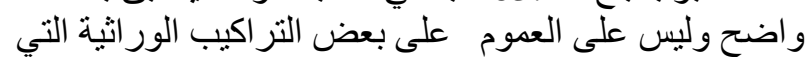

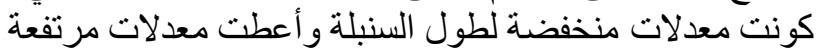

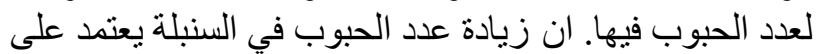

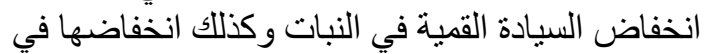

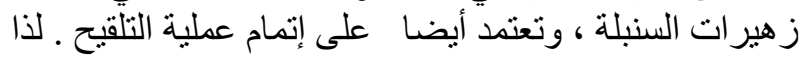

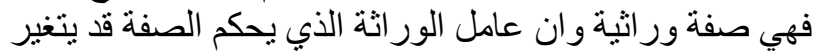

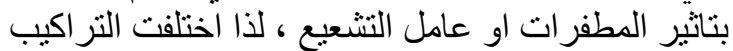

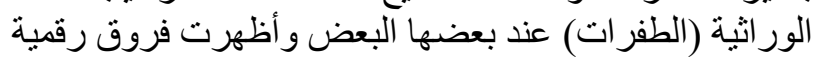
بين معدلات عدد الحبوب في السنبلة بعنة

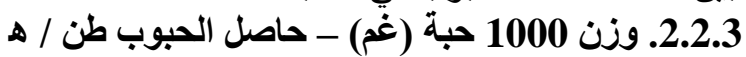

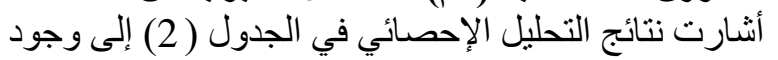

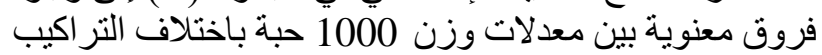

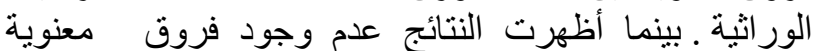

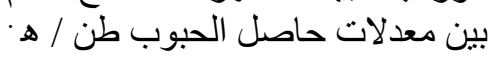

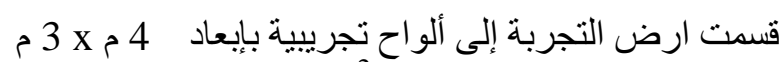

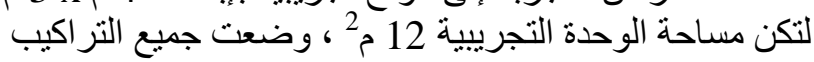

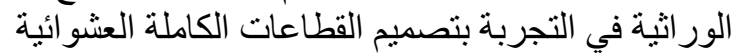
وبثلاثة مكررات ـ أضيف السماد المركب (الداب) (RCBD)

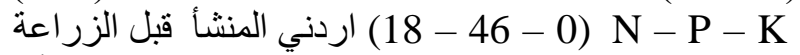

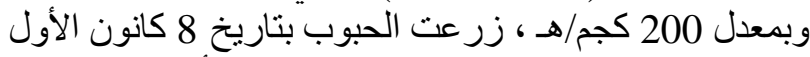

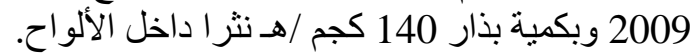

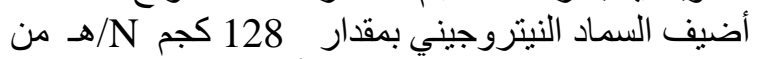

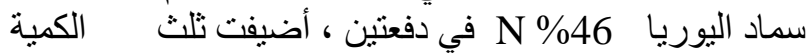

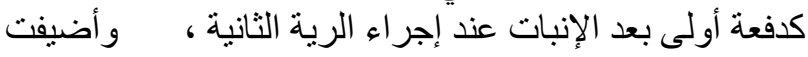

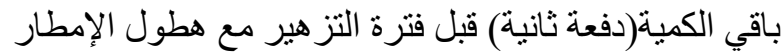

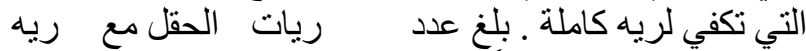

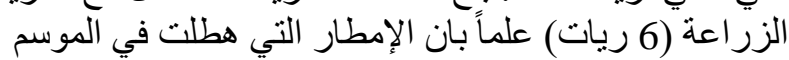

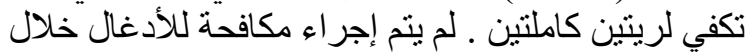

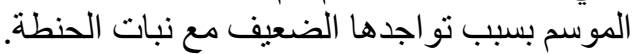

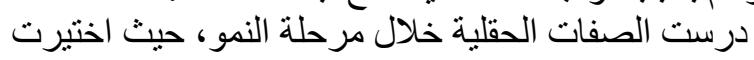

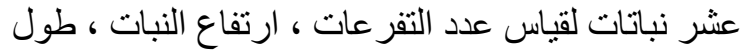

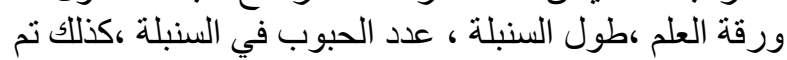

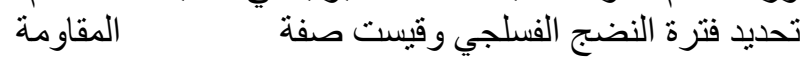

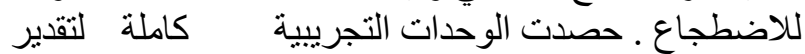

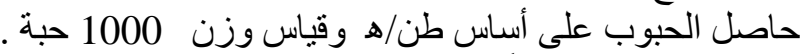

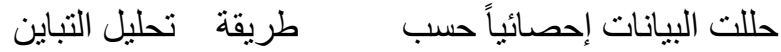

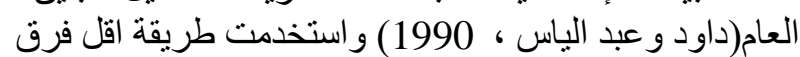

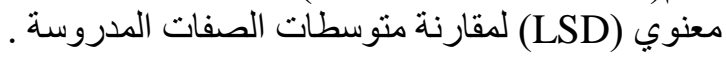

\section{3.التتائج والمناقشة}

1.3. صفات النمو الخضري

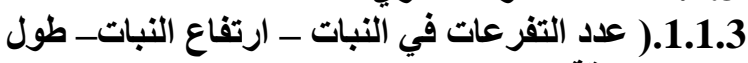

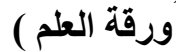

أثارت نتائج التحليل الإحصائي الواردة نتائجها في

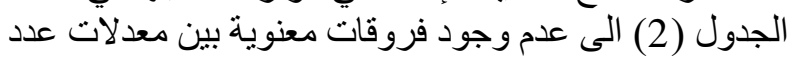

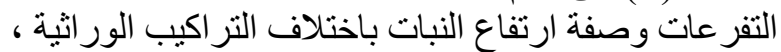

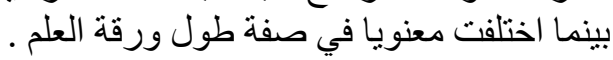

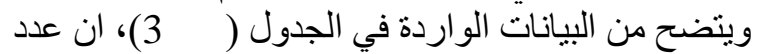

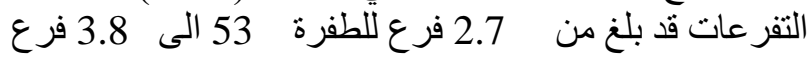

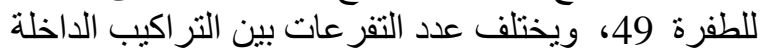

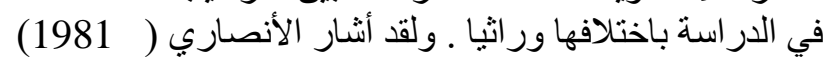

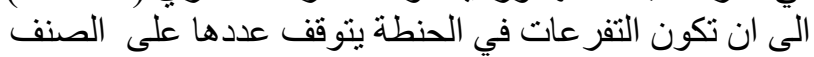

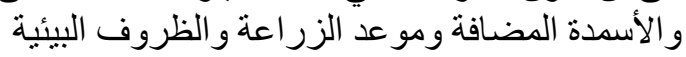

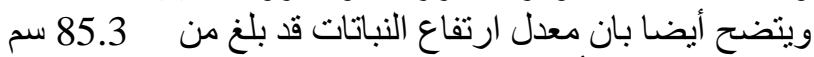

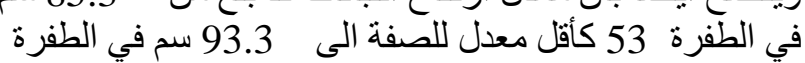

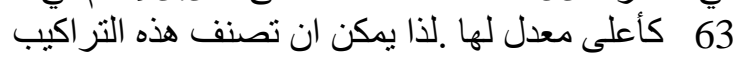

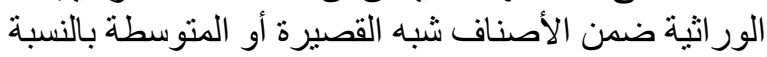

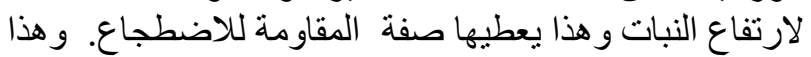




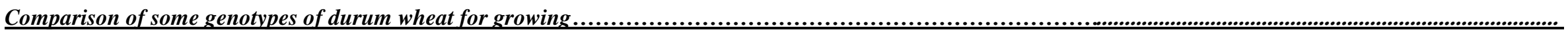

جدول (2) : قيم متوسط المربعات (MS) الناتجة عن التحليل الإحصائي للصفات المدروسة.

\begin{tabular}{|c|c|c|c|c|c|c|c|c|}
\hline \multicolumn{7}{|c|}{ الصفات المدروسة } & \multirow{2}{*}{ الحرية } & \multirow{2}{*}{ مصادر الاختلاف } \\
\hline حاصل الحبوب طن. هـ" & وزن 1000 حم) & عدالد الحبوبة في & طول السنبلة & طول ورقة العلم & $\begin{array}{c}\text { ارتفاع) النبات) } \\
\text { (سم) }\end{array}$ & عدد التفرعات في & & \\
\hline 0.018 & 68.913 & 0.780 & 0.232 & 2.405 & 18.762 & 0.058 & 2 & المكررات \\
\hline $0.321^{\text {n.s }}$ & $18.136 * *$ & $81.160^{\text {n.s }}$ & $\mathbf{0 . 3 3 0}^{\text {n.s }}$ & $19.524^{* * *}$ & $24.043^{\text {n.s }}$ & $0.349^{\text {n.s }}$ & 7 & التراكيب الوراثية \\
\hline 0.495 & 10.273 & 45.518 & 0.174 & 2.554 & 13.683 & 0.478 & 14 & الخطأ \\
\hline & & & & & & & 23 & الكلي \\
\hline
\end{tabular}

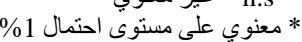

جدول (3): الصفات المورفولوجية وبعض صفات النمو والحاصل للتراكيب الوراثية في موسم 2009 /2010 ـ

\begin{tabular}{|c|c|c|c|c|c|c|c|c|c|c|c|}
\hline \multirow{2}{*}{ طبيعة نمو الأوراق } & \multirow{2}{*}{ لاضطجاعة } & \multicolumn{2}{|c|}{ النضج الفسلجي } & \multirow{2}{*}{ (طن/هـ-1-1 حاصل } & \multirow{2}{*}{ وزن حبة(غم) 1000} & \multirow{2}{*}{ في السنبلة } & \multirow{2}{*}{ السنبلة (سم) } & \multirow{2}{*}{ طول ورقة } & \multirow{2}{*}{ ارتفاع النبات } & \multirow{2}{*}{ عدد التفرعات } & \multirow{2}{*}{ التراثية } \\
\hline & & $\begin{array}{c}\text { طول (يوم) } \\
\text { (الفترة }\end{array}$ & ونهايته & & & & & & & & \\
\hline \multirow{3}{*}{ زاوية منفرجة ويشّل مع النبات } & متوسط & 12 & $\begin{array}{c}23 \text { - } 11 \\
\text { نيسان }\end{array}$ & 4.10 & 48.6 & 49.1 & 6.8 & 24.8 & 91.3 & 2.9 & حنطة خشنة \\
\hline & متوسط & 12 & $\begin{array}{c}23 \text { - } 11 \\
\text { نيسان }\end{array}$ & 4.05 & 42.9 & 49.0 & 6.6 & 24.1 & 87.2 & 3.2 & $\begin{array}{l}\text { Cod } 68 \\
26 \text { طفرة } \\
\end{array}$ \\
\hline & متوسط & 13 & $\begin{array}{c}25-12 \\
\text { نيسان }\end{array}$ & 3.66 & 45.2 & 50.2 & 6.4 & 23.8 & 91.5 & 3.4 & $\begin{array}{l}\text { Cod } 68 \\
38 \text { طفرة }\end{array}$ \\
\hline \multirow{7}{*}{ سطح التربة ولى اتثكل } & ضعيف & 12 & $\begin{array}{c}25-13 \\
\text { نيسLان }\end{array}$ & 4.62 & 37.4 & 63.1 & 6.0 & 19.3 & 86.4 & 3.1 & $\begin{array}{c}\text { Cod } 68 \\
7 \text { طفرة }\end{array}$ \\
\hline & ضعيف & 10 & $\begin{array}{c}26-16 \\
\text { نيسان }\end{array}$ & 4.42 & 34.7 & 56.6 & 7.0 & 21.4 & 88.6 & 3.8 & $\begin{array}{l}\text { Cod } 68 \\
49 \text { طفرة } \\
\end{array}$ \\
\hline & متوسط & 13 & $\begin{array}{c}26-13 \\
\text { نيسان }\end{array}$ & 4.40 & 40.5 & 51.3 & 6.7 & 18.0 & 85.3 & 2.7 & $\begin{array}{l}\text { Cod } 78 \\
53 \text { طفرة }\end{array}$ \\
\hline & متوسط & 13 & $\begin{array}{c}25-12 \\
\text { نيسان }\end{array}$ & 4.42 & 44.6 & $\mathbf{5 0 . 0}$ & 6.2 & 24.4 & 93.3 & 3.3 & $\begin{array}{l}\text { Cod } 68 \\
63 \text { طقرة } \\
\end{array}$ \\
\hline & ضعيف & 11 & $\begin{array}{c}28-17 \\
\text { نيسلان }\end{array}$ & 3.87 & 34.5 & 57.9 & 6.7 & 21.3 & 87.6 & 2.9 & $\begin{array}{l}\text { Cod } 68 \\
82 \text { طقرة }\end{array}$ \\
\hline & & & & N.S & 5.6 & N.S & N.S & 2.8 & N.S & N.S & $\begin{array}{l}\text { LSD } \\
0.05\end{array}$ \\
\hline & & & & $\% 16.77$ & $\% 7.8$ & $\% 12.62$ & $\% 6.36$ & $\% 7.22$ & $\% 4.16$ & $\% 21.7$ & C.V\% \\
\hline
\end{tabular}




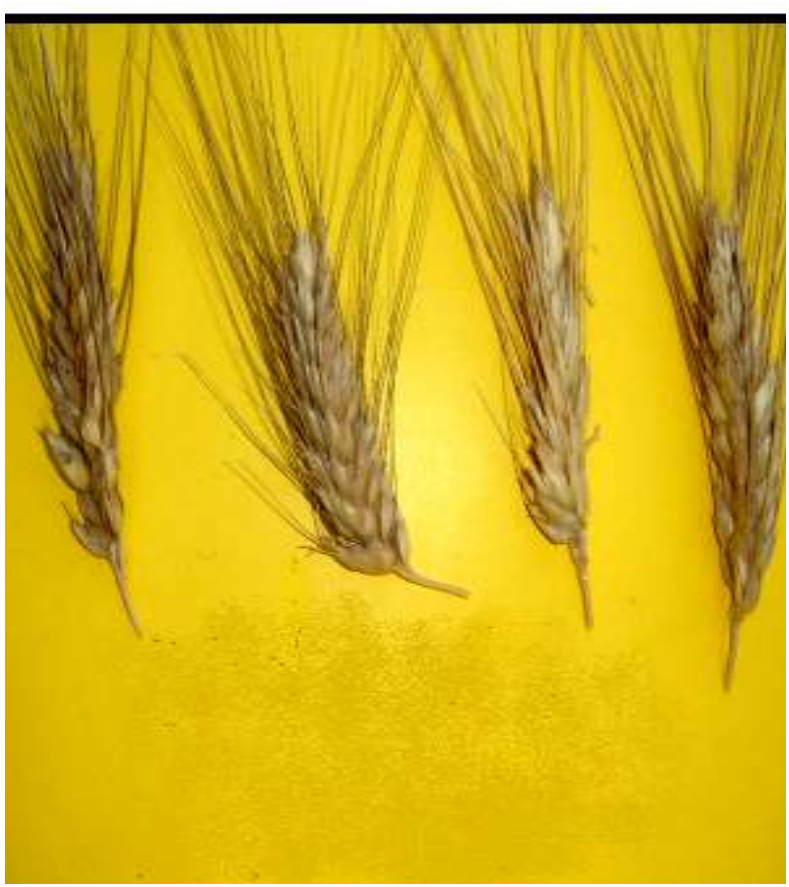

صورة رقم (2): سنابل الطفرة 26

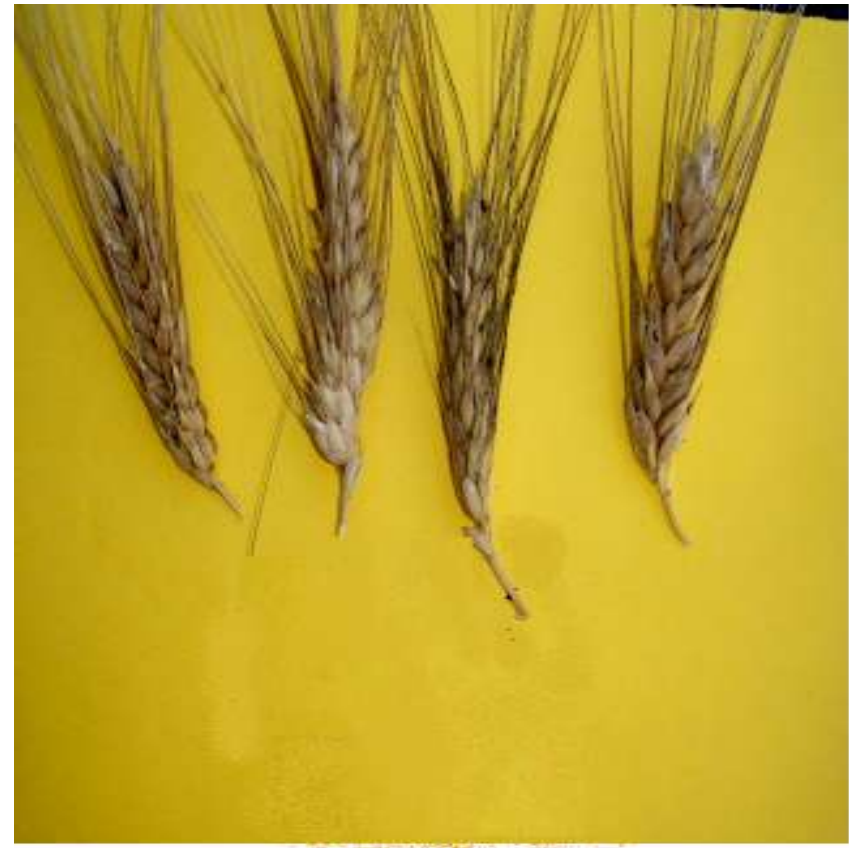

صورة رقم (4): سنابل الطفرة 38
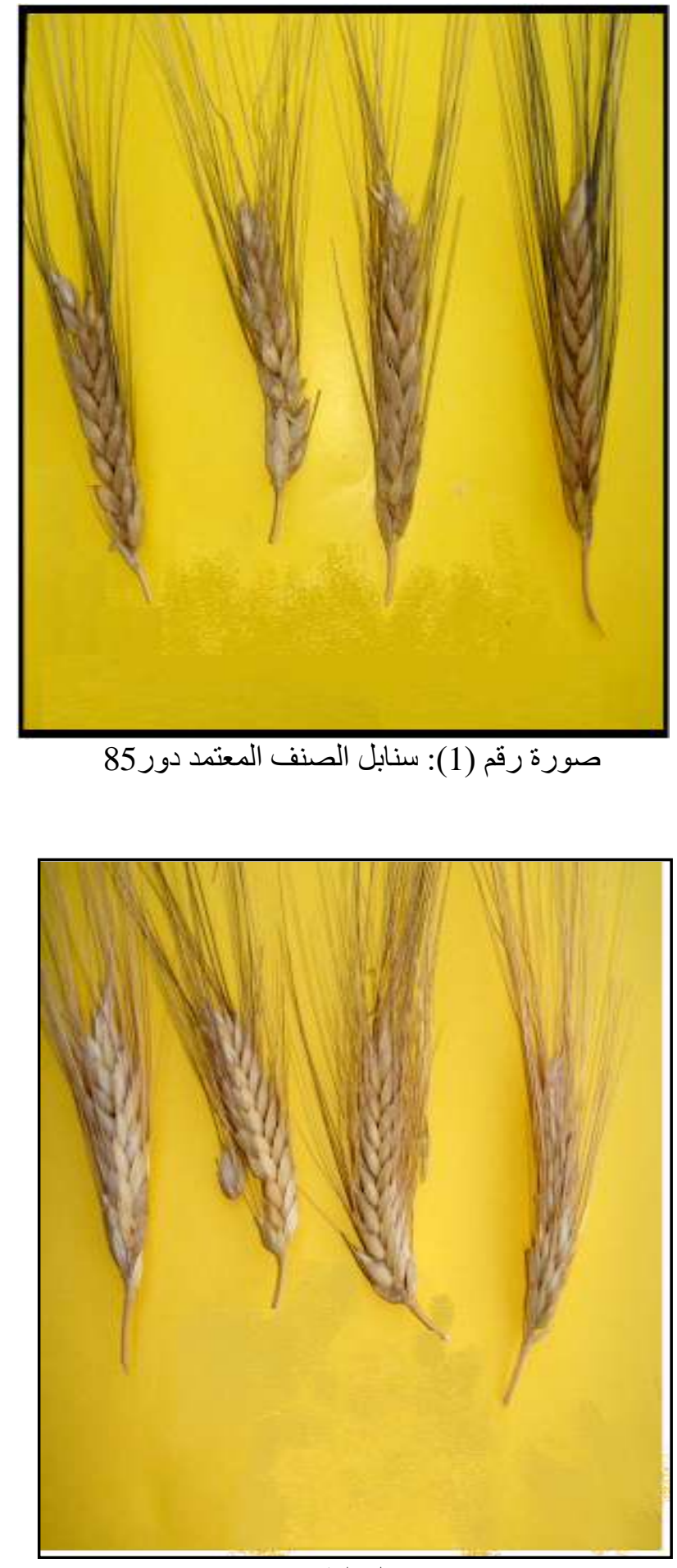

صورة رقم (3): سنابل الطفرة 7 
فقدان الرطوبة، وتكون الحبوب في مرحلة النضج الفسلجي

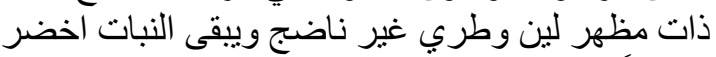
و وغضاً.

يتضح من الجدول (3) ان الطفرة (26) و الصنف المعتمد

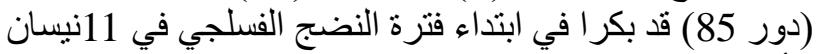

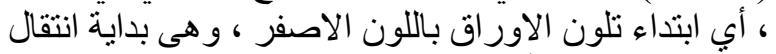

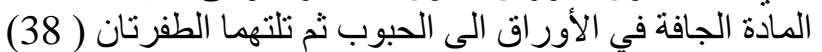
و (63) في 12 نيسان و الطفرتان ( ) ولان و (53) (53) في 13 نيسان

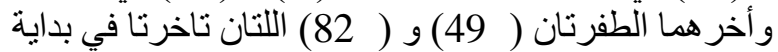

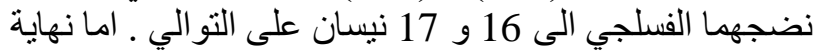

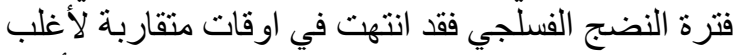

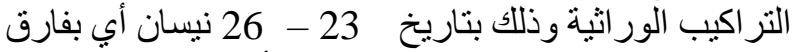
ثلاثة ايام باستثناء الطفرة (

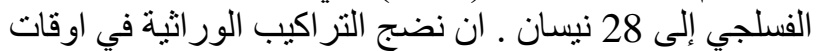

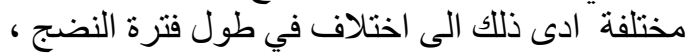

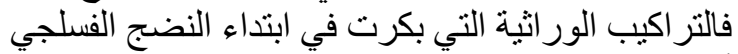

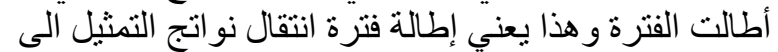

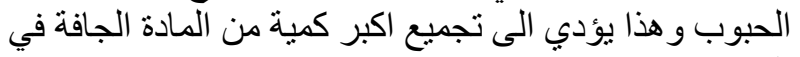

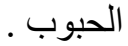

تجدر الإشارة هنا الى ان مربي النبات ير غب في تحديد

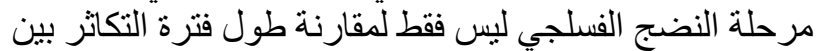

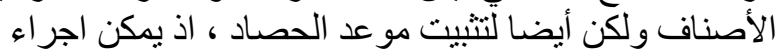

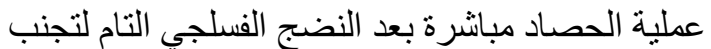
الانفر اط في حالة تأخر عمليات الحصداد وبخاصنة الحصاد

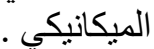
4.3. طبيعة نمو الاوراق

اتضح من خلال متابعة طبيعة نمو التر اكيب الور الثية الثية خلال

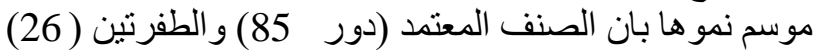

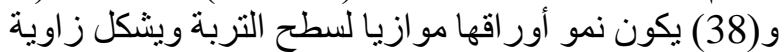
منفرجة مع س-اق النبات ـ بينما الطفرات ( ز82، يكون نمو اور اقها عموديا على اتجاه سطح الترات التربة ويشكل

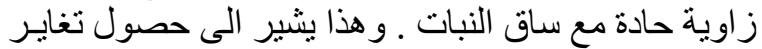

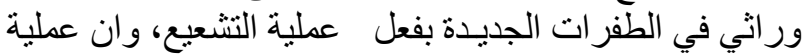
ترتيب الأوراق على الساق لها علاقة مباشرة بعملية التحلية التمثيل

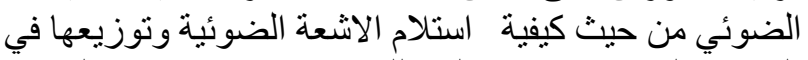

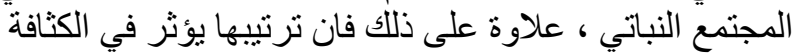

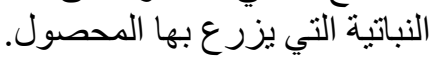

Warren لقد عرضت فكرة الاوراق القائمة من قبل

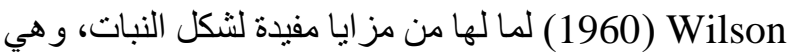

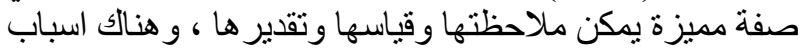

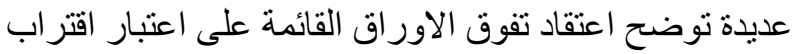

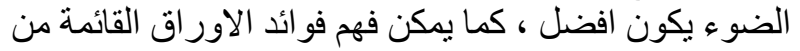

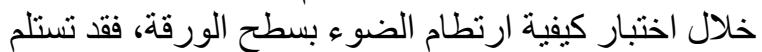

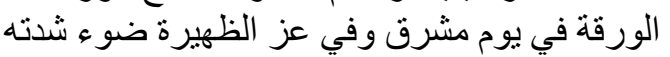

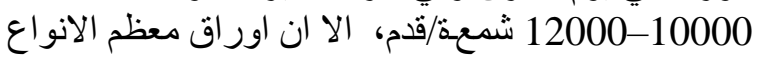

يتضح من الجدول ( 3) تفوق التركيب الور اثي (دور

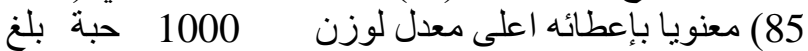

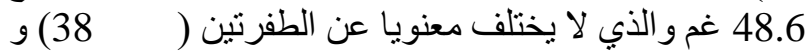

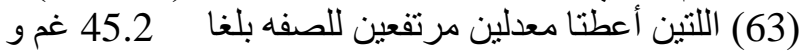

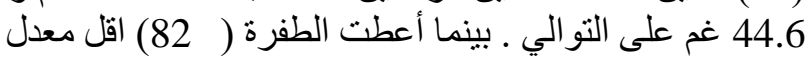

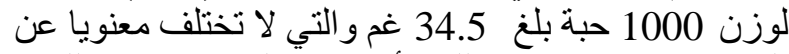

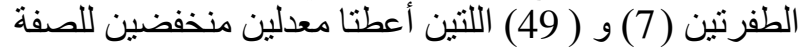

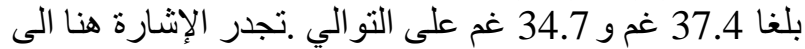

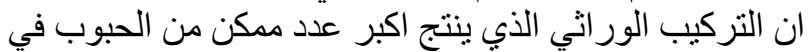

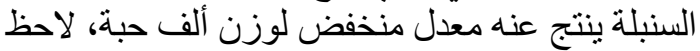

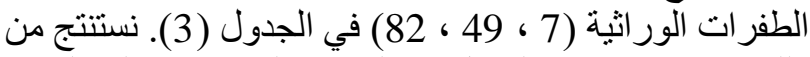

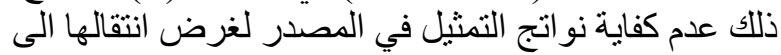

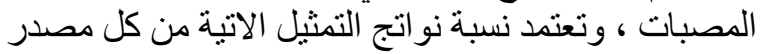
على التركيب الور اثي و البيئة . اظهرت نتائج التحليل الاحصائي و البيانات الوارئة التودة في

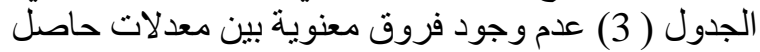

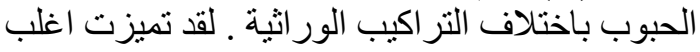
التر اكيب الور اثية في اعطاء حاصل عال في في وحدة المساحة،

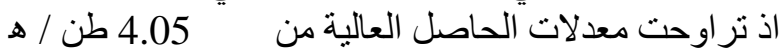

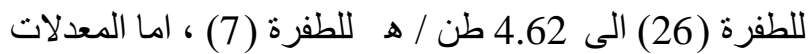

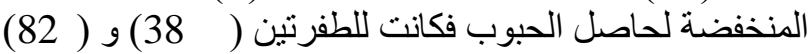

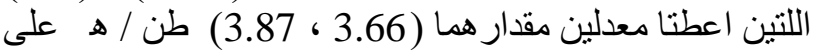

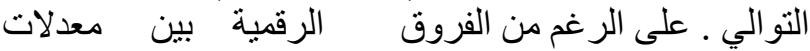

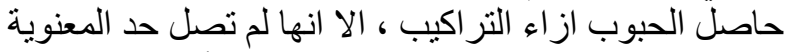

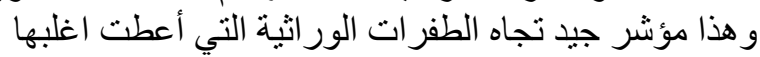

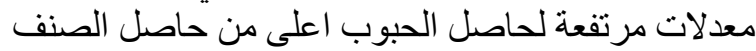

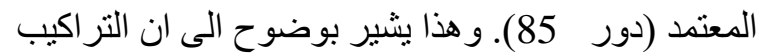

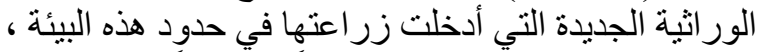

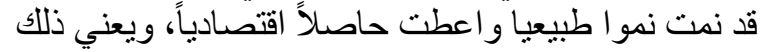

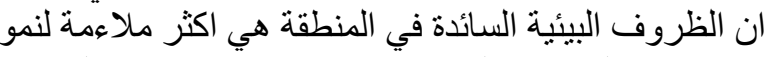

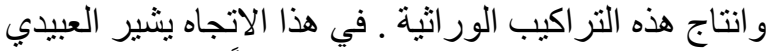

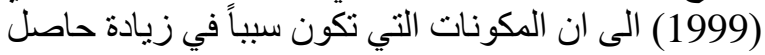

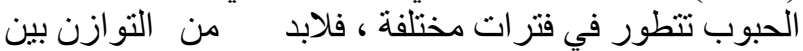

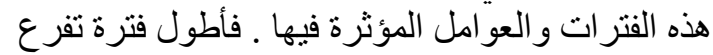

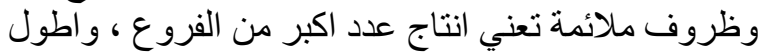

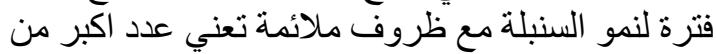

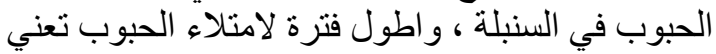

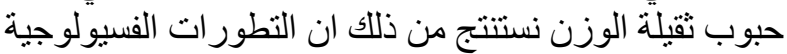

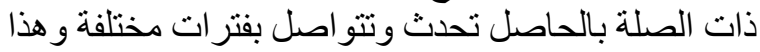
يفسح المجال لإعطاء فترة أطول للتأثير البيئي في صنئ

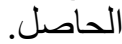
3.3. النضج الفسلجي

يمكن تعريف النضتج الفسلجي بانه اكتمال الفترة التكاثرية

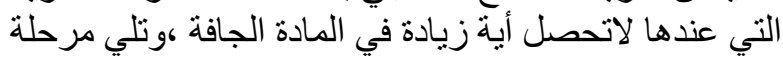
النضج الفسلجي مرحلة جفاف الحاصل الاقتصادي نتيجة 


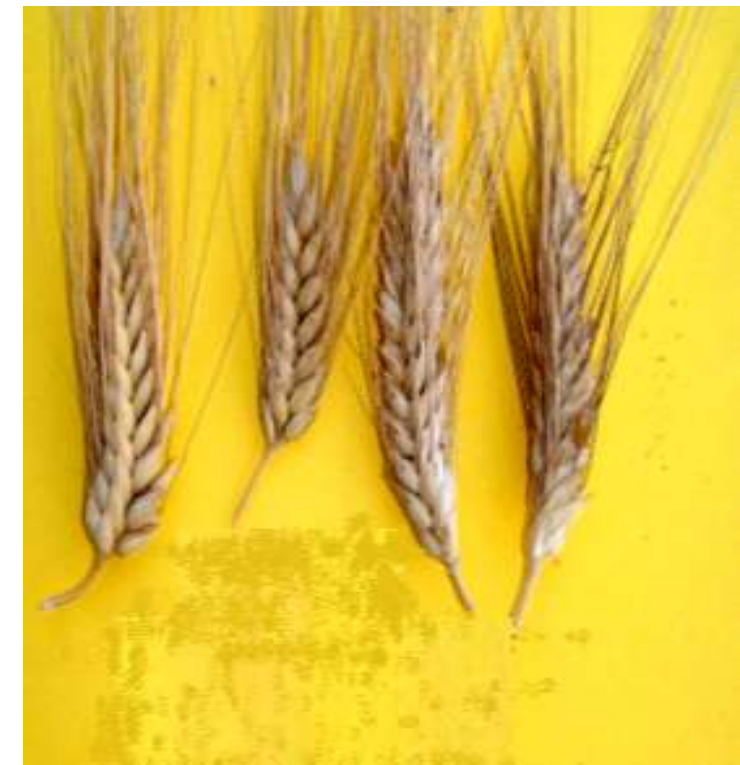

صورة رقم (6): سنابل الطفرة 53

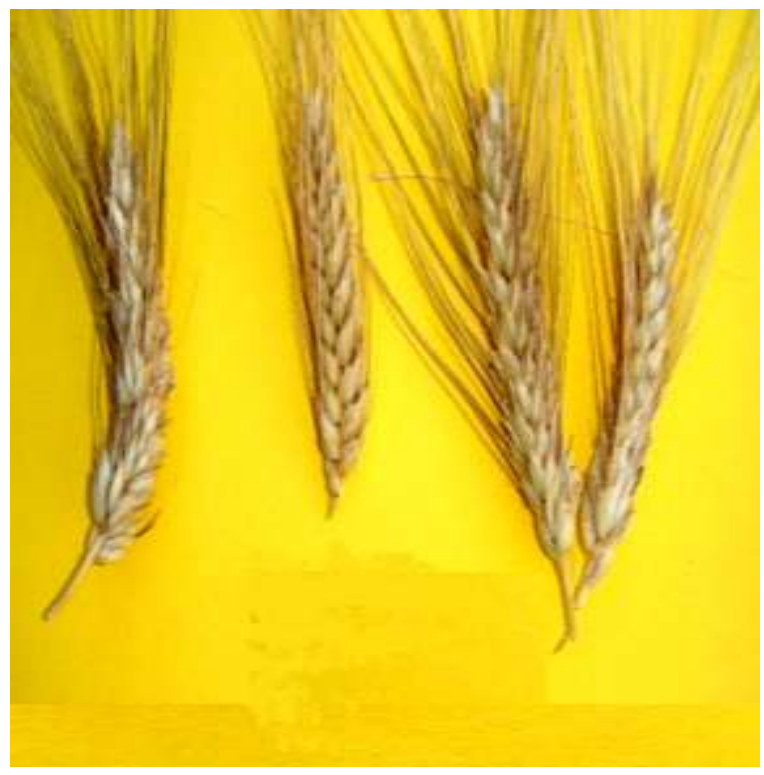

صورة رقم (8): سنابل الطفرة 82

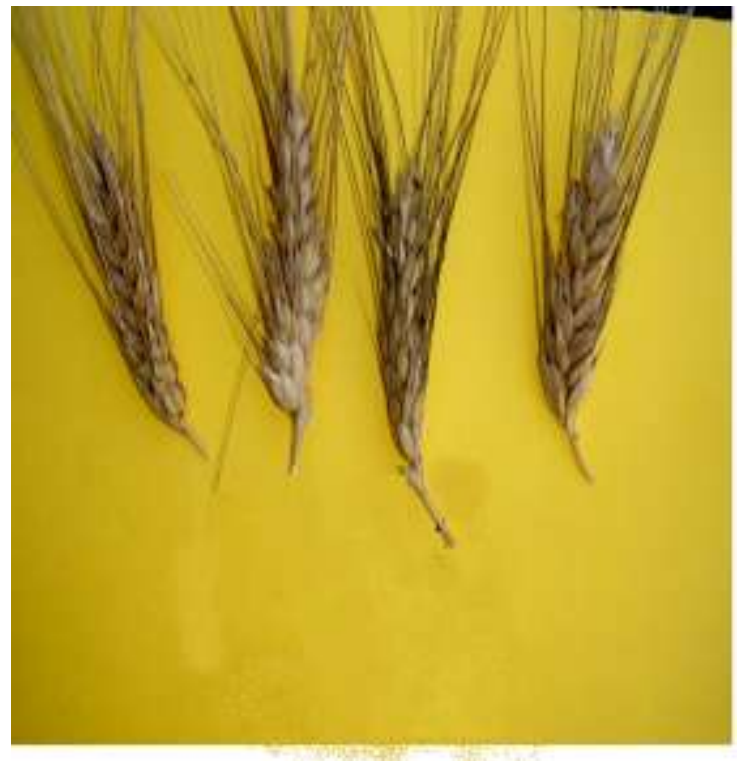

صورة رقم (5): سنابل الطفرة 63

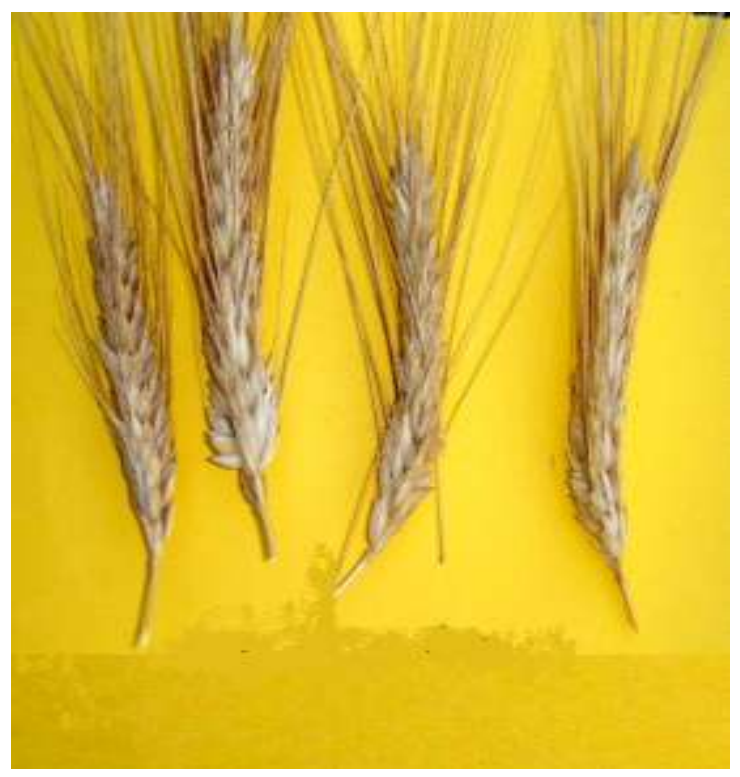

صورة رقم (7): سنابل الطفرة 49 
اصناف الحنطة خصوصا تحت الري السيحي، إذ ان الرقاد

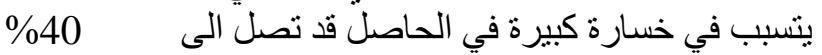
ويشير ستوسكوف (1989) الى ان الامر يتطلب معالجة مشكلة

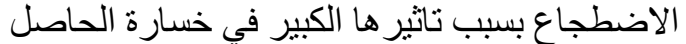

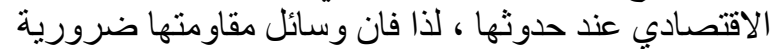
لزيادة انتاجية المحصول و هذا يتضمن استخدام وسائل التربية لإنية

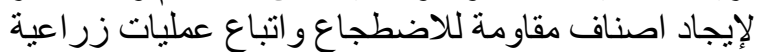

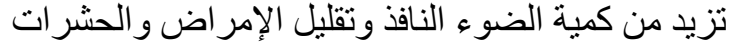

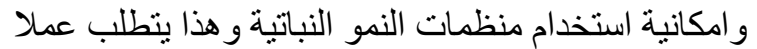

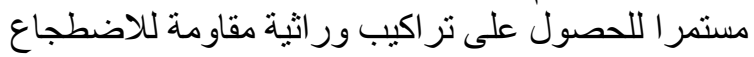

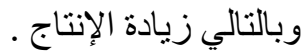

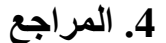

العبيدي، حمح عويد (2010). البرنامج العلمي لاستنباط أصناف جديدة من الحنطة الناعمة

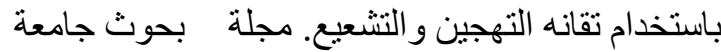
حلب،سلسله العلوم الزر اعية، العدد الصفحات1-14. العبيدي، مححد عويد غدير ( 1999) 19 التقويم عدد من التر اكيب

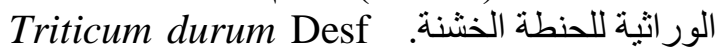

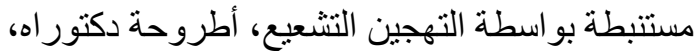

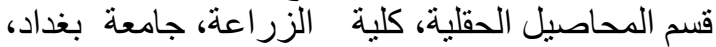

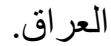

العبيدي، محمد عويد واسكندر فرنسيس إبر اهيم وهيثم عبد

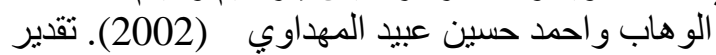
الثبات المظهري لبعض التز اكيب الور اثية من الحنطة

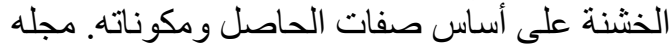
الزر اعة العر اقية (عدد خاص )، المجلد 7 ، العدد 4. عدد الصفحات 130- 136. الأنصاري، مجيد محسن (1981 ) إن إنتاج المحاصيل الحقلية . وزارة التعليم العالي و البحث العلمي ـ الجمهورية التئة العر اقية عدد الصفحات 323.

داود، خالد محمد وزكي عبد الياس، (1990). الطرق الإعة الإحصائية

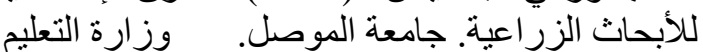

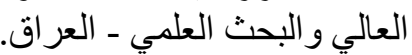
ستوسكوف، نيل ـ أس 1989 (فهم إنتاج المحاصيل)، ترجمة

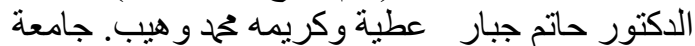

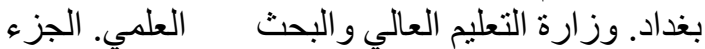

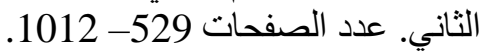

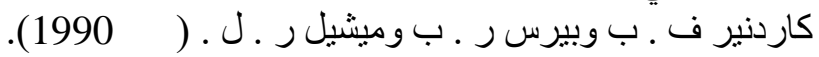

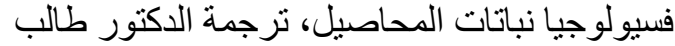

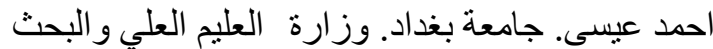
العلمي ـ عدد الصفحات 496.
النباتية تستخدم هذه الثده العاليه كما ان اعلى معدل تمثيل

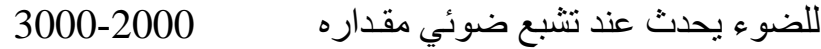

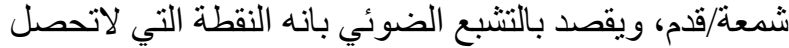

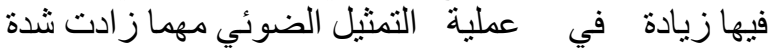

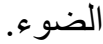

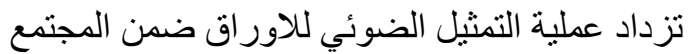
النباتي عادة بمقدار الضعف في حالة الاور القات القائمة

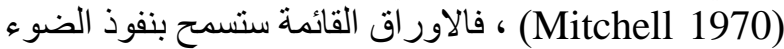

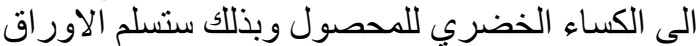
السفلى كمية ضو هُ كافية. ويشير (كاردينير و آخرون

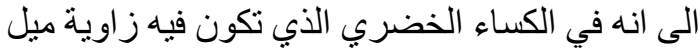

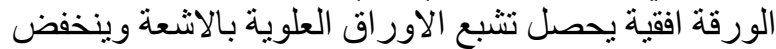

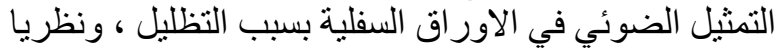

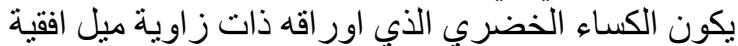

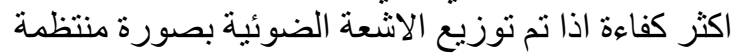
فوق سطح الاوراق.

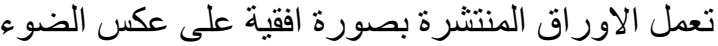

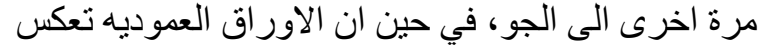

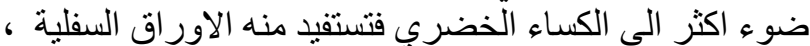

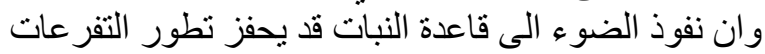

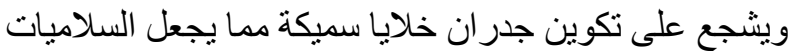

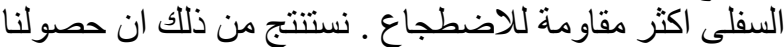

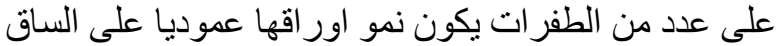

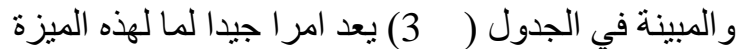

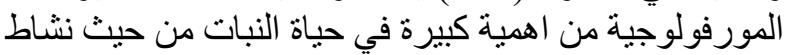
نموه وكفاءته في الانتاج. 5.3. صفة المقاومة للاضطجاع الات فئاج

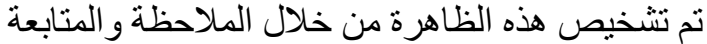

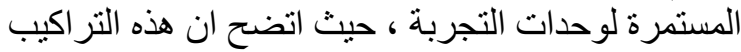

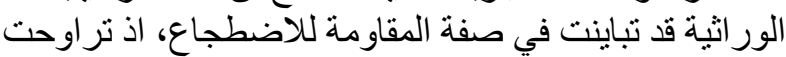

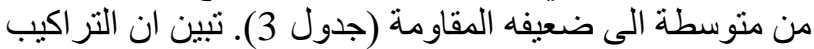

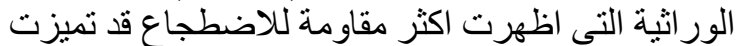

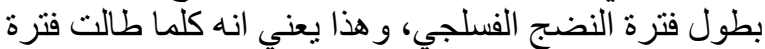

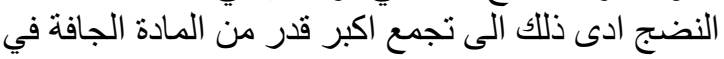

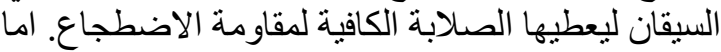

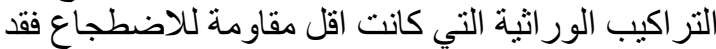

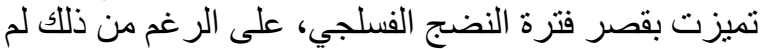

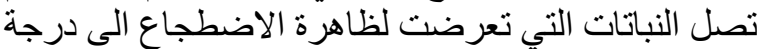
الحساسية التي تكون سبيا في اعاقة الحصاد التصاد الميكانيكي.

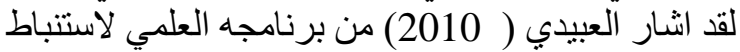
اصناف جديدة من الُنطة الناعمة باستخدام

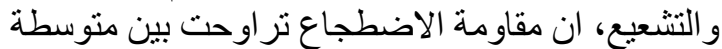

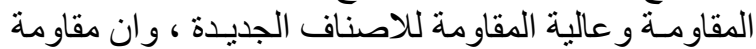

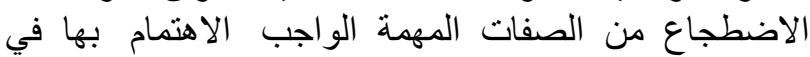




\section{REFERENCES}

Anna M. Mc Clung ., Cantrell R. G., Quick J. S and Gregory R.S. (1986). Influence of the Rhti semidwarf gene on yield, yield components, and grain protein in durum wheat. Crop . Sci., 6: 1095 - 1098.

Djelepov K. (1985). Utilization of experimental mutagenesis in wheat breeding Mut. Breeding Newsletter, IAEA, Vienna, 26: 7 - 8 .

Jain H . K ., Sinha S. K., Kuishrestha V.P. and Mathur V.S. (1973). Breeding for yield in dwarf wheats. Proc. of the $4^{\text {th }}$. Int. wheat Genet. Symp. Columbia Missouri, USA, pp . $527-532$.

Lebsock K.L. (1963). Transfer of Norin 10 genes for dwarfness to durum wheat . Crop Sci .; 3: $450-451$.

Micke A. (1979). Use of mutation induction to alter the ontogenetic pattern of crop plants. Gamma Field Symposia, Japan, 18: 1-23.

Mitchell R.L. (1970). Crop Growth and Culture. Ames. lowa: lowa State University press., P. 349.

Mosconi C., Rossi L. and Cecchini A. (1990). Mutagen treatment with mutant cross derive variety. Utation Breeding Newsletter, FAO/ IAEA, Vienna, 35:40 - 41.

Savor P. (1973). Results obtained after irradiation of some hybrid combination of common wheat. Sci. Session of the institute of Genetics, Sofia (Bulg. with Engl. Summary).

Warren Wilson J. (1960). Influence of Spatial Arrangement of Foliage Area on Light Interception and Posture Growth. Proceedings of the Eighth International Grassland Congress. Paper 12 A/2. pp. 275 - 279. 